\footnotetext{
FACULDADE DE MEDICINA DA UNIVERSIDAdE DE SãO PAULO 1. a Cadeira de Clínica Cirúrgica - Prof. Alípio Correia Neto
}

\title{
OCLUSÕES INTESTINAIS AGUDAS (*)
}

\author{
EURYCLIDES DE JESUS ZERBINI \\ Chefe de clínica - Livre Docente de Clínica Cirúrgica
}

A oclusão intestinal aguda póde ser definida como um estado 'mórbido, no qual se verifica uma parada mais ou menos rápida da progressão do conteudo intestinal, por um tempo mais ou menos longo, durante o qual se processam perturbações patológicas na alça ocluida, com repercussão para todo o organismo.

\section{CLASSIFICAC̨ÃO}

O número de agentes etiológicos capazes de provocar uma semelhante oclusão' é muito grande, porém, esse agente sempre atua por um dos tres mecanismos seguintes, o que permite fazer-se uma classificaçãa etiopatológica das oclusões intestinais em tres grandes grupos:

A) Oclusões mecânicas - São aquelas em que a obturação da luz intestinal se verifica graças a um obstáculo orgânico. Esșe obstáculo póde-se localisar na luz do intestino, em suas paredes, ou fóra delas. Porisso, do ponto de vista didático, admite-se uma subdivisão deste grupo em:

1) oclusões intraluminares.

2) oclusões intramurais.

3) oclusões extramurais.

Entre as primeiras, encontram-se as atrezias e estenoses congê- nitas do intestino delgado, do réto ou do anus, as estenóses inflamatórias produzidas por enterites ulcerativas (tuberculose, disenteria basilar, sífilis etc.), as oclusões provocadas por neoplasias que crescem para dentro da luz intestinal, as oclusões por corpos extranhos ao intestino e que estacionam em sua luz (cálculos, vermes, objetos, etc.) e finalmente as invaginações, em que ơ intestino é ocluido pela penetração de uma alça na outra.

Entre as oclusões intramurais, colocamos aquelas que se processam graças a um agente etiológico que provoque o espessamento das paredes intestinais a ponto de ocluir a sua luz. Podemos citar os traumatimos capazes de produzir uma contusão das paredes e consequente hematoma, e tambem, uma fibrose post-traumática da parede, consequente a um descolamento mesenterial. Tambem podem ocasio-

( (*) Parte da conferencia realisadá na Sociedade de Medicina e Cirurgia de São Paulc, em sessão de 6-8-1941, do C. A. O. C. 
nar uma oclusão intraparietal os tumores benignos ou malignos, porém, geralmente, estes processos ocluem a luz por crescerem para dentro dela.

Entre as oclusões, mecânicas extramurais, distinguimos um grande número de condições, capases de ocluir a luz do intestino, agindo por compressão de suas paredes de fora para dentro. Devemos lembrar que as mais frequentes oclusões estão classificadas neste sub-grupo, em que distinguimos:

a) oclusões por aderencias (30-40\%) que provocam acotovelamentos ou compressão do intestino e que podem ter uma origem congênita (brida de Lane etc.), inflamatória (apendicite supurada, anexite, peritonite tuberculosa etc.), traumática ou néoplasica;

b) oclusões por hernias estranguladas ou encarceradas (mais ou menos $45 \%$ );

c) oclusões por vôlvulos (mais ou menos 10\%);

d) oclusões por tumores extraintestinais;

e) oclusão arteriomesentérica, em que a porção transversa do duodeno é ocluida pela artéria mesentérica superior;

f) oclusão por um desenvolvimento anormal do intestino.

B) Oclusões nervosas - No segundo grupo da classificação de acordo com o agente produtor da oclusão, encontramos os ileos produzidos por um agente capaz de alterar a inervação da musculatura das paredes do intestino, provocando, seja a sua paralisia (ileo paralítico ou adinâmico), seja um espasmo dessa musculatura (ileo espástico ou dinâmico).

C) Oclusões circulatórias - No terceiro grupo estão as oclusões produzidas por um agente que interfere com a suplencia circulatória da alça (ileos circulatórios) e devemos distinguir as embolias das arterias mesentéricas (infarto anêmico), as tromboses das veias mesentéricas (infarto hemorrágico) e, o chamado espasmo vascular post-traumático.

\section{CLASSIFICAC̨ÃO ETIOPATOLOGICA DAS OCLUSOOES INTESTINAIS}

I - O'clusões mecânicas.

A) intra-luminais

1) congênitas

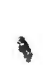
2) adquiridas

B) intra-murais

1) traumatismos

a) atresia e estenose intestinais.

b) atresia do anus

a) inflamações (tuberculose, sífilis, di-

senteria bacilar, etc.).

b) néoplasias $(10 \%)$.

c) corpos extranhos (cálculos, vermes,

objetos, etc.).

d) invaginações (5\%).

2) néoplasias $\left\{\begin{array}{l}\text { benignas. } \\ \text { malignas. }\end{array}\right.$

hêmatomas.

descolamento mesentérico e fibrose parietal. 
C) extra-murais

$\begin{array}{ll}\text { 1) aderências } & \left\{\begin{array}{l}\text { congênitas. } \\ \text { inflamatớrias. } \\ \text { traumáticas. } \\ \text { neoplásicas. }\end{array}\right. \\ \text { 2) hérnias } \\ (44 \%) & \left\{\begin{array}{l}\text { estranguladas. } \\ \text { encarcéradas. }\end{array}\right.\end{array}$

3) vôlvulos (10-50\%).

4) tumores.

5) erros do desenvolvimento.

6) ileo artériomesentérico.

II - Oclusões por perturbações nervosas.

A) ileo paralítico ou adinâmico.

B) ileo espástico ou dinâmico.

III - Oclusões por insuficiência circulatória.

A) embolia mesentérica (infarto anêmico).

B) trombose mesentérica (infarto hemorrágico).

C) espasmo vascular traumático.

Estes tres mecânismos de produção de ileo podem agir concomitantemente comó é o caso nos vôlvulos, nas invaginações e nos estrangulamentos por bridas ou por hérnias. Nesses casos, ø mesmo agente que oclue mecânicamente "a luz da alça intestinal, pơde provocar uma insuficiência circulatória parcial ou absoluta e portanto um ileo circulatório; esta condição, por sua vez, acarreta a produção de edema, que altera a função dos plexos nérvosos. Portanto, o mesmo agente prộduz, ao mesmo tempo, um ileo mecânico, circulatório e nervoso.

Parạ haver uma oclusão não é necessário que a luz do intestino esteja absolutamente ocluida, sua musculatura completamente paralisada e se encontre uma insuficiência circulatória completa; pelo contrário, a ação parcial e combinada destes agentes pode provocar um ileo, quando um deles, só por si, poderia ser insuficiente para provoca-lo.

De todas estas formas de oclusões, a mais frequente é o estrangulamento provocado por hérnias. As estatísticas americanas avaliam em $44 \%$ a sua frequencia; na $16^{\mathrm{a}}$ cadeira desta Faculdade, observamos, durante 4 anos, 29 casos de oclusões mecânicas, das quais 21 eram provocadas por hérnias estranguladas ou encarceradas. Em segundo lugar estão as oclusões por bridas, cuja frequencia é avaliada entre 30 e $40 \%$ e das quais reunimos 3 casos. Quanto às outras modalidades de oclusões ,observa-se, singularmente, que existe uma verdadeira distribuição geográfica das diferentes formas. Assim, as invaginações intestinais que são raras em todos os paizes (mais ou menos $5 \%$ ) constituem a forma mais frequente de oclusões na Inglaterra, Dinamarca e Australia. Quanto ao vôlvulo (ileo por torsão de alça) verifica-se que na Russia e na Servia, é o mecanismo responsavel por $50 \%$ das oclusões, ao passo que nos outros paizes apenas alcançam 10\%. BRAUN e WORTMANN procuraram relacionar este fato com o fatôr alimentar, mostrando que, em determinadas partes da Russia, o dolicocolo é frequente (20\% dos individuos), podendo-se 
explicar esse fato pela alimentação vegetariana, que requer maior permanência nos colons para sua fermentação.

Pondo-se de lado o fatôr etiológico e levando-se em consideração as condições anatomo-patológicas da oclusão, os ileos podem ser distinguidos em dois grandes grupos;

1 - ileo simples, que é aquele em que se verifica unicamente uma parada da progressão do conteudo intestinal, sem se verificar concomitantemente nem estrangulamentó da luz da alça ocluida, nem lesões dos vasos que se destinam à alça.

2 - ileo estrangulado, ou ileo com estrangulamento, em que se pode verificar unicamente um desaparecimento da luz, ou, ao mesmo tempo, um estrangulamento da luz da alça e dos vasos que se destinam a esssa mesma alça. Estes são os casos mais graves de oclusões intetinais, poís, com a insuficiência circulatória que se estabelece, diminue de muito a viabilidade da alça; pode sobrevir uma necrose por anemia das paredes do intestino, sua perfuração e consequente peritonite mortal (fig. n. ${ }^{0} 1$ ). Contudo, basta a necrose da parede para que o peritonio possa ser contaminado, ou diretamente pela passagem dos germes atravez da parede que se torna permeavel, ou, pelos trajetos linfáticos que drenam o conteudo da alça, nos quais os germes continuam em evolução.

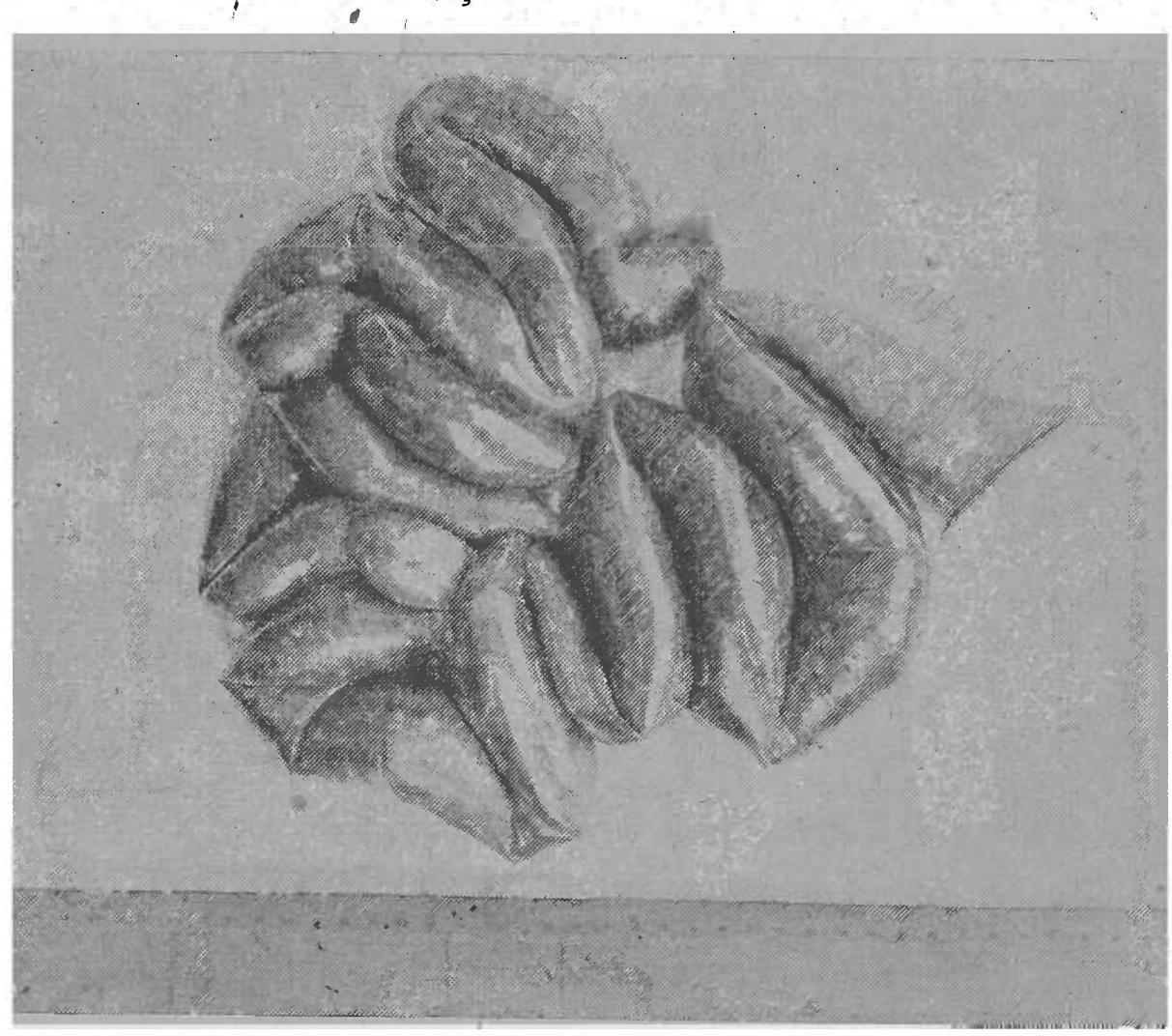

FIG. 1

Peça operatória ressecada em ưm caso de oclusão aguda do delgado (estrangulamento por brida). Paciente operado por apendicite supurada ha 12 anos; quadro de-oclusẵo inteștinal aguda ha 72 horas. Cerca de $2 \mathrm{mts}, 50$ do intestino delgado achavam-se estrangulados por uma brida que se extendia do céco à parede abdominal; essa alça estava completamente necrosada e em alguns pontos prestes a romper-se, pelo que foi considerada não viavel e ressecada. 
Do ponto de vista anatomo-patológico existe uma grande diferença entre os casos de oclusão em um único ponto ou oclusão em dois ou mais pontos de u'a mesma alça.

a) si uma alça do intestino delgado é ocluida em um único ponto, verifica-se, dentro de algum tempo, um acúmulo de líquido e de gazes a montante ao ponto de oclusão; esse gaz em sua maior parte provem dos gazes da deglutição, muito ricos em Az., que não é normalmente absorvidó. Esse material distende a alça, numa porção maior ou menor, a partir do ponto de oclusão, de acordo com o tempo durante o qual o intestino permanecer ocluido; entretanto, a pressão no interior da alça não alcança nunca um grau tão elevado, para provocar pertứrbações na circulação da parede intestinal, o que explica a relativa benignidade desses ileos.

b) ' si a oclusão se realisa em dois ou mais pontos do intestino, forma-se o.que se denomina alça de Wahl, e as lesões anatomo-patológicas que se verificam são geralmente muito mais graves do que aquelas que se observam nas oclusões em um único ponto. $\mathrm{O}$ gaz, que normalmente transita pelo intestino, origina-se de duas fontes: $70 \%$ do gaz é deglutido com os alimentos e quasi todo ele é constituido por azoto, não absorvivel; os $30 \%$ restantes são formados por um gaz autógeno, que se desprende na luz intestinal, ou pelas trocas com o sangue (oxigênio e anidrido carbônico, ambos absorviveis). ou, que se forma graças aos processos de fermentação (hidrogênio metana, amônia, gaz -sulfídrico, etc., todos não absorviveis, e anidrido carbônico, absorvivel). Após a oclusão da alça em dois pontos, o gaz que se origina da deglutição não mais alcança o interior da alça de Wahl; porém a quantidade de gaz de fermentação que normalmente é pequena, torna-se muito maiór, provocando uma elevação da pressão dentro da luz intestinal. Em consequencia disso, a absorpção pela mucosa dessa alça altera-se e não tarda a desaparecer completamente; porém, o líquido que já existe nessa alça ocluida é muito rico em substancias protêicas, que se destinavam ao sangue do sistema porta; porisso, forma-se um meio hipertônico em relação ao plasma, e resulta uma corrente osmótica centrífuga que aumenta a quantidade de líquido dentro da luz do intestino. Mas, com isso, a pressão intraluminar torna-se maiór e alcança a pressão normalmente existente nos capilares venosos da parede do intestino, provocando o seu bloqueio; mas 'o sangue continua a ser comprimido no sistema capilar, graças à pressão sistólica dos capilares arteriais, e, não tarda sobrevir uma corrente de plasma para dentro da luz intestinal e outra para a cavidade peritonial; pouco a pouco vai-se estabelecendo o quadro de um infarto hemorrágico. Com mais essa grande quantidade de líquido, a pressão, dentro da alça, eleva-se alcançando aquela que existe nos capilares arteriais da parede do intestino, e, sobrevem o infarto anêmico. Seguem-se então todas as consequencias desastrosas de uma anemia tissular aguda, capaz de provocar o aparecimento de ulcerações, necrose e perfuração da alça ocluida, lançando-se para a cavidade peritonial, todo aquele líquido, rico em germes virulentos e substâncias tóxicas do seu 
metabolismo; dentro da alça, esșas substancias não eram absorvidas, pois a absorção da mucosa está anulada pela pressão, mas, no peritonio livre e praticamente normal, ha uma absorção em massa, colapso tóxico, e morte.

$\mathrm{O}$ grosso intestino constitue, até certo ponto, uma excepção a esta regra, porque a sua oclusão em um único ponto é capaz de determinar a formação de uma alça de Wahl, pois a válvula de Bauhin pode ser infranqueavel no sentido retrógrado, o que nem sempre se verifica.

Deante de uma alça ocluida em dois pontos, e que apresenta sinais de insuficiência circulatória, o cirurgião é chamado a avaliar a sua viabilidade; se os processos de anoxemia aguda forem irreparaveis, a alça deve ser ressecara (fig. 1), porém, em easo contrário, a alça deve ser conservada. Para julgar dessa viabilidade, após desfazer a oclusão, o operador deve verificar tres pontos importantes: a) volta da coloração normal espontaneamente ou após lavagem cơm sôro fisiológico aquecido; b) movimentos peristálticos presentes e provocados por piparotes e c) batimento dos vasos mesentéricos.

\section{FISIOLOGIA PATOLÓGICA}

Ao lado das alterações anatomo-patológicas na alça ocluida, os. portadores de oclusão intestinal apresentam um quadro toxêmico geral, que os leva, mais ou menós rapidamente, à morte. Desde muito tempo, tem-se observado que as oclusões altas; nas primeiras porções ¿o trato gastro-intestinal, são muito mais graves que as oclusões das porções terminais do intestino. As experiencias clássicas são as de Hartwell e de Hoguet (1912). Esses autores usaram cães, nos quais realisaram uma laparatomia e a ligadura do intestino logo após o piloro; observarám que esses animais apresentavam, sempre, vômitos incoerciveis eliminando grande quantidade de líquidos, e, vinham a falecer em um tempo muito curto (cerca de 48 horas). Observaram tambem esses autores, que se ministrassem uma razoavel quantidade de cloreto de sódio a esses cães assim operados, eles poderiam entrar em um estado de adaptação, no qual poderiam viver até 30 dias. Os dois autores citados levantaram, então, a hipótese de que, dentro da alça ocluida, forma-se uma quantidade muito grande de substâncias tóxicas, que são absorvidas ,e, matam o animal por intoxicação; ainda mais, lançaram a hipótese de que o cloreto de sódio é uma anti-toxina ou um antídoto desses venenos que são absorvidos da luz do intestino distendido pela oclusão.

Essas ideias sobre a patogenia da intoxicação nos casos de ileos duraram até pouco tempo atraz, quando varios autores e, principalmente OWEn Wangensteen, mostraram que a absorção atravez da mucosa intestinal, está muito diminuida ou completamente abolida, quando "existe uma distensão das paredes da alça em questão. $\mathrm{O}$ autor citado, mostrou mais, que nos animais intensamente intoxicados por uma oclusão antiga, não se verifica a presença de tais súbstâncias tóxicas 
(Drincioamente

(principalmente a histamina) no sangue circulante. $\mathrm{E}$ ainda, verificou que não havia uma semelhante absorção porque, se retirasse 0 sangue que drena de uma alça ocluida, em um animal moribundo por uma velha oclusão, e o injetasse na veia de um outro animal, este não apresentava os sinais da intoxicação. Procurou-se, então, novas explicações para a toxemia que sempre acompanha as oclusões intestinais, até que se teve a ideia de estudar os componentes químicos do sangue dos animais em oclusão experimental. WANGENSTEEN repetiu as experiencias de Hartwell e Hoguet, verificando que os cães com oclusão alta apresentavam uma grande baixa no clo̊ro, um aumento do azoto não proteico no sangue circulante e morriam em um estado de alcalose; verificou tambem que, com a ministração de cloreto de sódio, havia um restabelecimento dos valores do cloro e do azoto e uma correção do $\mathrm{pH}$ sanguineo.

Hoje sabe-se que a toxemia durante a oclusão intestinal é fruto das alterações profundas que sobrevêm no metabolismo do cloro, da agua e do azoto.

a) metabolismo do cloro durante as oclusões.

Nas oclusões das primeiras porções do intestino delgado verifića-se que o animal de experimentação ou o doente, entram rapidamente em um regimen de vômitos incoerciveis, eliminando grande quantidade de líquido. Esse líquido é constituido, principalmente, por suco gástrico e portanto é rico ácido clorídrico. Aos poucos, vai se processando a eliminação de grande quantidade de ácido clorídrico, que leva o organismo a uma espoliação aguda de cloro. Em consequencia disso, ha uma baixa pronunciada do cloro no sangue ou seja uma hipocloremia, sempre acompanhada por uma baixa do cloro na urina ou seja uma hipocloruria; verifica-se que os valores do cloro no sangue e na urina podem ser reduzidos á metade de seus valores normais.

Entretanto, o cloro não existe no sangue em estado de liberđade, mas está associado ao sódio, sob a forma de cloreto de sódio. Com a dissociação deste elemento em ions $\mathrm{Cl}$. e $\mathrm{Na}$. e posterior eliminação de parte do estóque de cloro pelo suco gástrico, verifica-se, no sangue, grande quantidade de ions $\mathrm{Na}$. em estado de dissociação; parte desses ions $\mathrm{Na}$. entra em combinação com o radical $\mathrm{CO}_{2} \mathrm{OH}$, que sempre existe, formando grande quantidade de bicabornato de sódio que leva, rapidamente, o animal de experimentação ou o paciente portador de oclusão, a um estado de alcalose compensada ou descompensada, de acordo com a duração da molestia. A porçẩo restante dos ions $\cdot \mathrm{Na}$., livre no plasma, é eliminada pelo rim, proyocando um estado de hipernatrúria transitória; como consequencia dessa espoliação do sódio do sangue, sobrevem um estado de hiponatremia (baixa de sódio do 'sangue)

b) metabolismo da agua durante as oclusões.

$\mathrm{O}$ organismo necessita grande quantidade de agua para que as suas trocas metabólicas se processem regularmente. $E^{\prime}$ sabido que um individuo de 70 quilos tem 45 de agua. Sabe-se tambem que o individuo não suporta uma redução dessa agua sinão dentro de limites muito 
pequenos: assim, quando se perde $10 \%$ desse estóque de agua, sobrevem graves perturbações, e, a perda de $20-22 \%$ é inexoravelmente mortal. Podemos comparar, então, a importância da agua com os outros. elementos do organismo quando lembramos que o individuo suporta. a perda de $100 \%$ de suas gorluras e $50 \%$ das suas proteinas (o seu peso reduz-se de $40 \%$ mas continua a viver).

Pois bem, nos individuos que apresentam oclusão intestinal alta,. verifica-se uma espoliação aguda e intensa da agua por dois motivos. Em primeiro lugar, a agua não se fixa nos tecidos, porque o metabolismo hídrico tissular é garantido principalmente pelo sódio, e os válores desses ions $\mathrm{Na}$ estão muito reduzidos. Em segundo lugar, a agua é eliminada em quantidade fabulosa pelos vômitos, tão intensos e tão precoces. Neste particular observa-se que as oclusões supra-vaterianas, dentro de sua gravidade, são mais benignas que as infra- vaterianas, porque, nas primeiras, o líquido eliminado é sómente o súco gástrico, ao passo que nas segundas, eliminam-se tambem as secreções bilio-pancreáticas. Sabemos, que normalmente esse líquido gastro-bílio-pancreático derramado na luz do trato gastro-intestinal alcança cerca de 7.500 ccs. nas 24 horas; porem essa grande quantidade de líquido é novamente absorvida pelo delgađo e pelo céco. Acresce ainda o fato de que durante as oclusões essa quantidade de líquido eliminada é muito maior que aquela que normalmente é secretada para a luz intestinal, pois, com a oclusão, distenção e peritaltismo aumentado, tanto a secreção gástrica, como a bílio-pancreática, acham-seexageradas.

Após algumas horas de vômitos incoercíveis, sobrevem um estado de grave desidrataçã̀o, que o médico pode reconhecer peló aưmențo da viscosidade do sangue, pelo aumento relativo do número: de seus elementos figurados e da taxa de hemoglobina, pela desidratação da pele e da lingua, pela concentração da urina, etc. ; esse estado leva rapidamente à morte.

c) metabolismo do azoto durante as oclusões

O metabolismo normal das proteinas é muito complexo; entretanto, do ponto de vista didático, ele pode ser esquematisado nas se- guintes fases:

As proteinas são absorvidas pela mucosa intestinal sob a forma. de aminoácidos, os mais simples, e levadas pelo sangue do sistema porta até as células hepáticas. Aí, essas substancias sofrem um processo de desaminação, sendo, então, transformadas em albuminas do sangue, sôro albumina e sôtớ-globulina, e sob essa forma, lançadas na corrente circulatória. Por essa via hemática, a proteina alcança os. tecidos, onde vai servir a seu metabolismo, sendo depois devolvida ao sangue, sob formas azotadas mais simples, ácido úrico e polipeptideos. Essas substâncias voltam pela via hemática para o fígado, onde são novamente modificadas pela célula hepática e novamente devolvidas ao sangue, som forma de uréia. Essa uréia do sangue é então eliminada pelos rins. Como se vê a quantidade que normalmente existe, no sangue, de polipeptideos, ácido úrico e uréia, é regulada pela fun- 
ção do fígado e do rim e pelo metaholismo tissular. Mas este, é regido diretamente pelo sódio e pelo cloro, e principalmente pelo cloro, de tal sorte, que, uma redução dos valores do cloro é capaz de provocar uma perturbaçãó metabólica tissular. Durante os estados de oclusão intestinal, ha uma hipocloremia mais ou menos acentuada, e, em consequencia desta, sobrevem uma alteração do metabolismo de todos os tecidos do organismo, uma desassimilação azotada geral, que se caracterisa pelo lançamento de enorme quantidade de polipeptideos e ácido úrico, para a corrente circulatória. Estas substâncias são parcial ou totalmente clivadas, de acordo com a capacidade funcional do fígado, do que resulta a formação de grande quantidade de uréia,"lançada para o sangue e eliminada pelo rim. Mas o rim é então 'obrigado a levar ao máximo a sua capacidade de concentração, afim de eliminar muita uréia; entretanto, o individuo está em um estado de profunda desidratação e esta capacidade do rim tem agora um limite pouco maleavel. O menór grau de insuficiência renal, traduz-se por um acúmulo da uréia no sangue circulante e, portanto uma hiperazotemia. Logo a célula hepática torna-se incapaz de clivar uma. quantidade tão exagerada de polipeptideos e ácido úrico do sangue, $\mathrm{o}$. que-agrava a hiperazotomia e provoca uma hiperpolipeptidemia. A. dosagem do azoto total e' dos polipeptideos no sangue e na' urina sãoíndices para se avaliarem estas perturbações do metabolismo azotado nos quadros de oclusão intestinal.

Quando a oclusão intestinal se processa na parte terminal do ileo, ou nos colons, o quadro mórbido é muito diferente daquele que acabamos de descrever. Verifica-se que o animal com oclusão do ileo terminal vive satisfatóriamente durante um tempo razoavel, mesmo sem a ministração de cloreto de sódio, e só tardiamente, apresenta vômitos e toxemia; entretanto, quando esta aparece, o cloreto de sódio. não é capaz de prolongar a sua vida. Estês fatos, confirmados pela observação clínica, são explicados. Na oclusão baixa, os diferentes eletrólitos, particularmente os ions $\mathrm{C} 1$. e Na. são tambèm lançados para dentro da luz intestinal, porem são novamente absorvidos pelo intestino e não são eliminados. Por isso, a oclusão baixa é mais benigna que a oclusão alta. Esses fatos sómente são válidos para as oclusões. em que não se forma uma alça de Wahl. Nestes casos, e particularmente nas oclusões do grosso intestino, grande quantidade de líquido, rico $\mathrm{em}$ cloro, permanece em estase dentro da alça ocluida em dois pontos, como estudamos nas alterações anatomo-patológicas. Portanto, continua a haver uma espoliação do organismo em cloro e em agua, pois que a absorção na alça distendida exageradamente, não mais se verifica.

\section{BASES GERAIS PARA O TRATAMENTO DA OCLUSÃO}

Do que acabamos de estudar sobre a patologia da oclusão intestinal podemos tirar as premissas mais importantes, sobre as quais se fundamenta o tratamento dos pacientes portadores de semelhante estado mórbido. As finalidades desse tratamento são tres: 
a) correção das alterações metabólicas gerais.

b) correção das alterações patológicas locais.

c) restabelecimento da função intestinal pela remoção da causa da oclusão.

\section{CORREÇÃO DAS ALTERAÇÓES METABOLICAS GERAIS}

Esta finalidade fica preenchida mediante a restauração do equilíbrio hídrico e do equilíbrio eletrolítico.

$O$ equilíbrio hídrico é restaurado pela ministração de agua sob todas as formas, e, por todas as vias. A forma mais prática de se minisirar agua consiste no emprego de sôro físiológico isotônico pela via subcutanea, empregando-se $3-4.000$ ccs., de acordo com'o grau de desidratação do paciente; entretanto, pode-se ministrar pela via endovenosa, sob a forma de venóclise continua, grandes quantidades de sôro fisiológico. O sôro fisiológico é preferivel ao glicosado pois torna-se mais um veículo importante do cloro, que tanta falta faz ao paciente. A ministração de agua pelas vias naturais ou pelo réto deve ser evitada.

A restauração do equilíbrio eletrolítico é conseguida mediante a ministração de cloro. Quasi todas as alterações fisiológicas existentes na oclusão resultam de uma espoliação do organișmo em cloro. A função do médico consiste em garantir o capital clorado à disposição do individuo, para que esse ion $\mathrm{Cl}$. não falte, afim de garantir o metabolismo tissular; dessa maneira, com um único medicamento, faremos a prófilaxia não só da hipocloremia, mas corrigiremos tambem o metabolismo do azoto, que não é outra cousa que a consequenciae o deficit clorado. A ministração do cloro, faz-se sob a forma de sôro cloretado hipertônico, a $20 \%$, pela via endovenosa; a quántidade a ser empregada, varia naturalmente com o grau de intoxicação do paciente. Para uma orientação mais positiva, o cirurgião deveria recorrer-se, a cada momento, do laboratório, verificando o teor do plasma em cloro; a quantidade de sôro cloretado a ser ministrada dependeria dessas dosagens. Entretanto, sob o ponto de vista prática essas dosagens repetidas são irrealisaveis, pois, exigem um determinado tempo para serem corretamente executadas, quando o estado do paciente exige medidas rápidas. Então, são os sinais clínicos, como Q estado de intoxicação e a agitação do paciente, a desidratação da lingua, os exames rápidos como a concentração da urina, a taxa de hemoglobina, etc., que orientam o médico. Geralmente, empregam-se $180-200$ ccs. de solução a $20 \%$ de cloreto de sódio nas 24 horas, em doses fracionadas de 20 ou 40 ccs. cada uma.

A ministração de sôro glicosado hipertônico e insulina pode ser vantajosa para melhorar a fixação da agua nos tecidos.

\section{CORREÇÃO DAS ALTERAÇÕES PATOLOGICAS LOCAIS}

Todas as perturbações patológicas locais, na alça ocluida, são conséquencia da distensão da referida alça, e, por isso, a descom- 
pressão deve ser imediata. Essa descompressão pode ser conseguida por duas maneiras: "pela intubação intestinal seguida de aspiração, e pela enterostomia.

M. EINHORN, em um interessante artigo, reuniu uma série de estatísticas sobre casos de oclusão intestinal, mostrando uma evidente redução da mortalidade, nas séries mais recentes. Assim, as observações feitas em grande numero de ocluidos, antes de 1930, por Guillaume, Arhurst e Miller, oferecem, respectivamente, na mortalidade de $63,2 \%, 69,3 \%$ e $61 \%$; por outro lado, as estatísticas mais recentes, publicadas por Moss, Boyce e NoRTH, verificadas igualmente em grande número de pacientes, mostram a mortalidade de $31,7 \%, 36,3 \%$ e $29,2 \%$, respectivamente.

Essá grande redução da mortalidade deve ser atribuida, em parte, ao diagnóstico precoce e ao aperfeiçoamento da técnica cirúrgica, porém, a sua principal causa foi a introdução sistemática da descompressão imediata das alças intestinais. Com auxilio dessa medida terapêutica, a intervenção pode ser adiada, até que as condições gerais do paciente tenham melhorado, e o equilibrio hídrico e químico esteja restabelecido; "a operação torna-se então, um processo de eleição e não de emergência".

A descompressão das alças intestinais, com auxilio de uma sonda de borracha, foi usado, pela primeira vez, por Kussmaul e CaHN, em 1884, e tambem por LEviN, em 1921. Porém, a introdução sistemática do processo, com bases experimentais e clínica, deve ser atribuida a WANGENSTEEN. Este autor introduzia pela boca do paciente uma sonda de Levin, que apresentava alguns orificios em sua extremidade distal, adaptando um dispositivo de aspiração, na extremidade externa da sonda; assim, logo que a sonda alcançava o estômago, todo o seu conteudo era aspirado (fig. 2a). Em seguida, a sonda era levada para o duodeno, e a aspiração do conteudo intestinal iniciava-se. Porèm, os inconvenientes deste tipo de sonda foram logo percebidos, pois, um acúmulo de liquido no estômago, após a passagem da sonda pelo piloro, não poderia ser aspirado (fig. $2 \mathrm{~b}$ ).

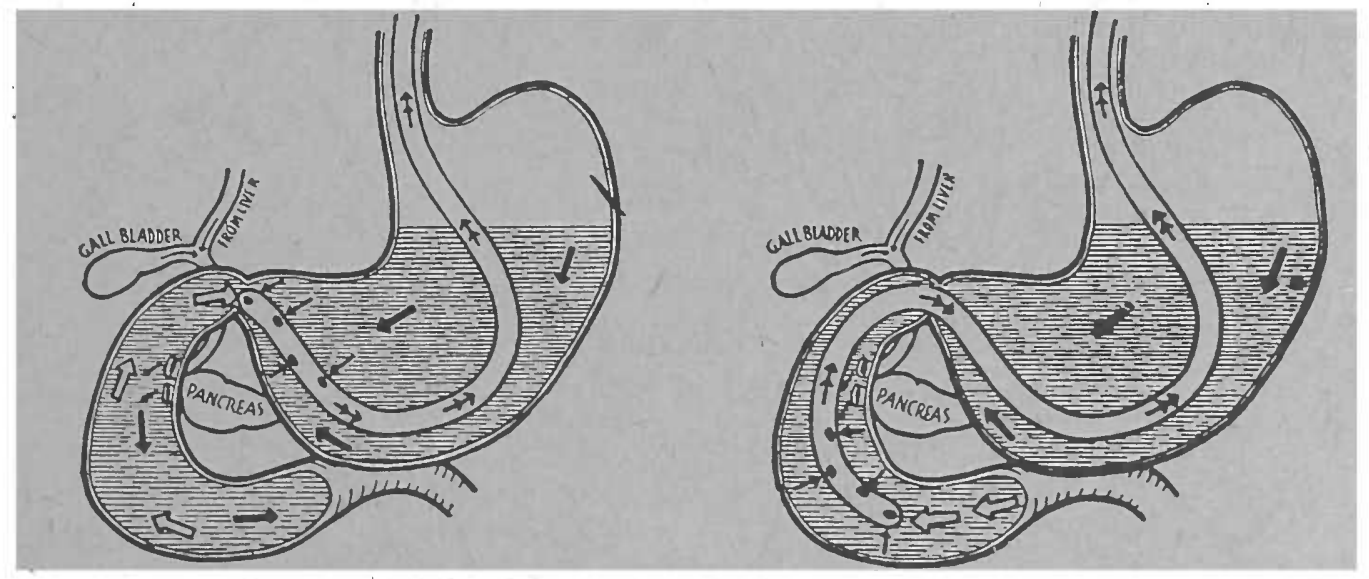

Frg. 2

Esquema da aspiração do conteudo gastro intestinal, com auxilio da sonda de Levin: a) Aspiração do conteudo gastrico; b) Aspiração do conteudo intestinal conservando o conteudo gástrico.

(M. Einhorn). 
Para evitar esses inconvenientes, Wangensteen, propoz o uso da sonda que traz o seu nome, e que se caracterisa pelo fato de apresentar varios orificios nas últimas. 10 polegadas, esperando, assim, conseguir uma aspiração simultanea do estômago e do duodeno. (fig. 3).

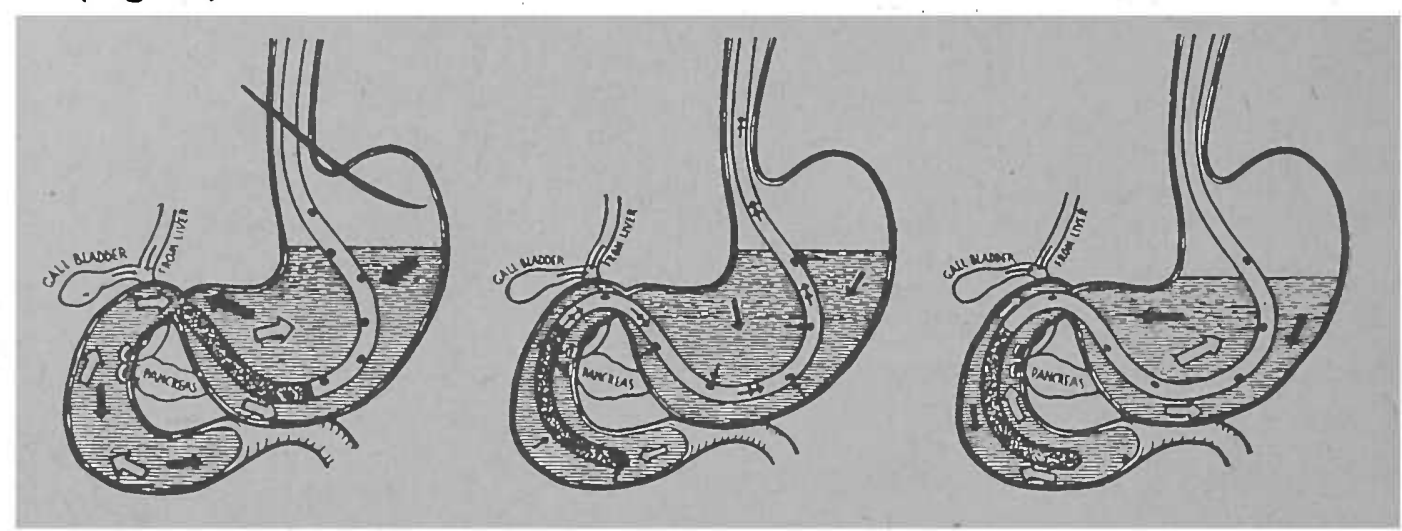

FIG. 3

Sonda de Wangensteen aplicada em um caso de oclusão; os esquemas mostram a possibilidade de se obter, ao mesmo tempo, a aspiração 1 do conteudo gástrico e intestinal.

(M. Einhorn).

M. Einhorn, fazendo um estudo experimental da sonda de Wangensteen, mostrou a impossibilidade de se realizar uma aspiração correta, com auxilio desse tipo, pois que, todas as vezes que os orificios superiores da sonda estiverem colocados acima do nivel líquido do estômago, toda aspiração somente retira gaz, mas não aspira o líquido. Para evitar esse inconveniente propoz um novo tipo de sonda (sonda de EINHORN) que se caracterisa pelo fato de apresentar uma dupla luz interior; trata-se portanto de uma sonda dupla, apresentando orificios terminais em um dos compartimentos e orificios altamente situados no outro (fig. 4).

Assim , aspirando-se, sucessivamente, um e outro compartimento da sonda, descomprimiremos o estômago e o intestino.

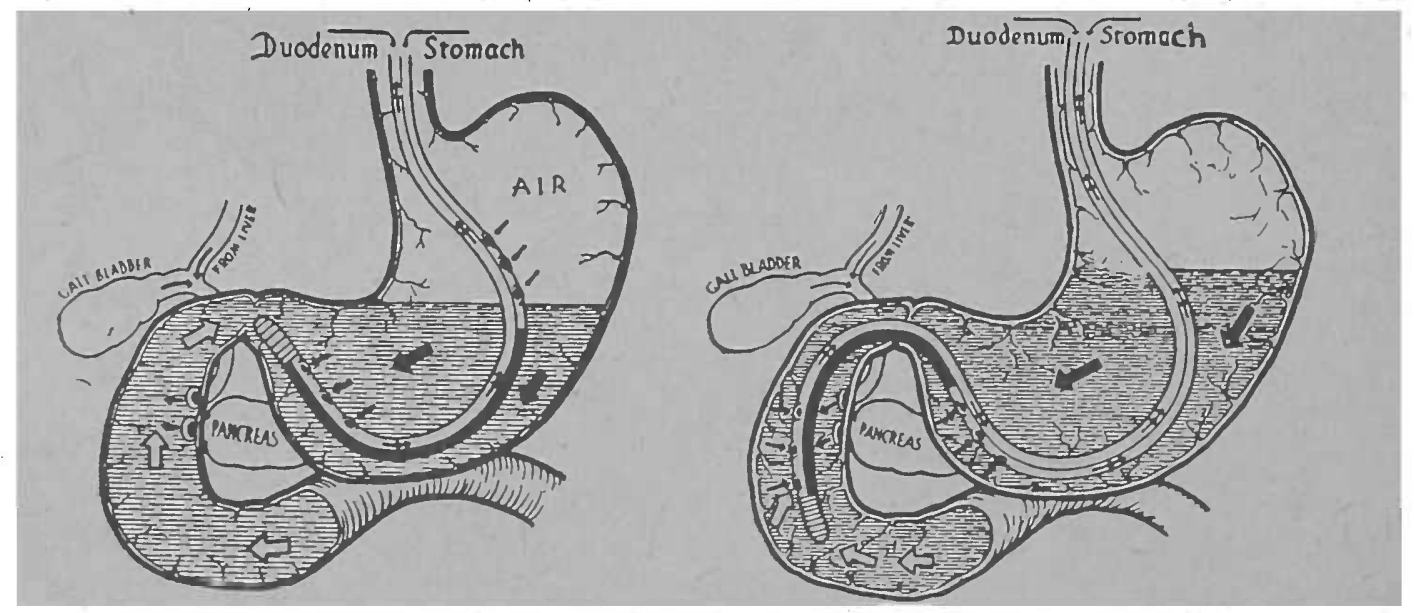

Frg. 4

Sonda dupla de Einhorn. Somente assim é possivel uma aspiração simultanea do estômago e intestino.

(M. Einhorn). 
Hoje, as sondas mais empregadas são as sondas duplas de MillerAbbot e de Einhorn. A sonda de Miller-Abbot é dupla, e apresenta uma porção distal com uma oliva, aquem da qual existe um pequeno balão. Quando a sonda é introduzida até o duodeno, o pequeno balão é insuflado e estabelece-se um sistema de aspiração contínua em sua extremidarle externa, (fig. 5). Dessa maneira, o conteudo de uma determinada porção da alça é aspirado e a alça đ'escomprimida, até que suas paredes internas entrem em leve contato com o balão insuflado, cujo diâmetro é pouco menór que aquele de uma alça intestinal. O contato com o balão desperta o peristaltismo nas paredes da alça descomprimida, e o tubo pode então progredir no interior do intestino, até a alça subjacente, onde o conteudo é aspirado novamente e o processo se repete. Assim, todo o conteudo intestinal é aspirado, e, se a oclusão é mecânica, o tubo caminha até o ponto ocluido, e, aí permanece, drenando o líquido e o gaz que constantemente se acumula. Se a oclúsão se processa por um ileo adinâmico, o mecanismo é o mesmo; o tubo é levado pelo peristaltismo até a alça paralisada; aspira o seu conteudo, descomprime as suas paredes, e, o peristaltismo reaparece novamente.

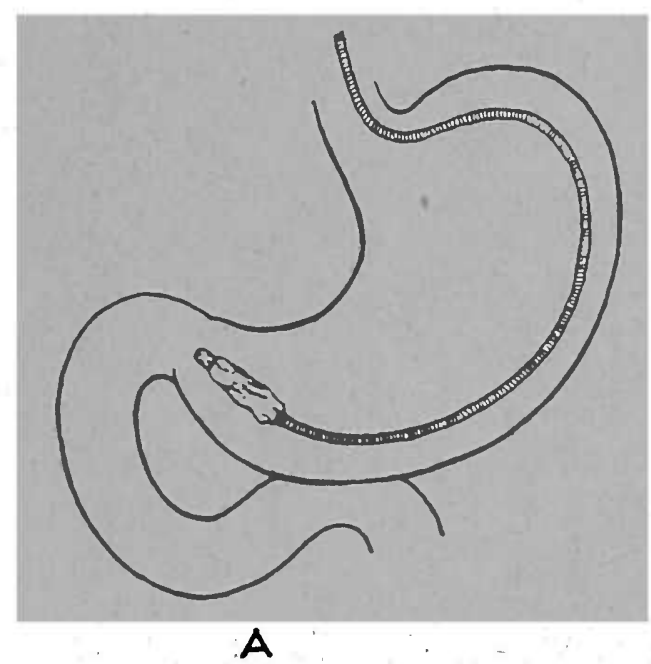

A

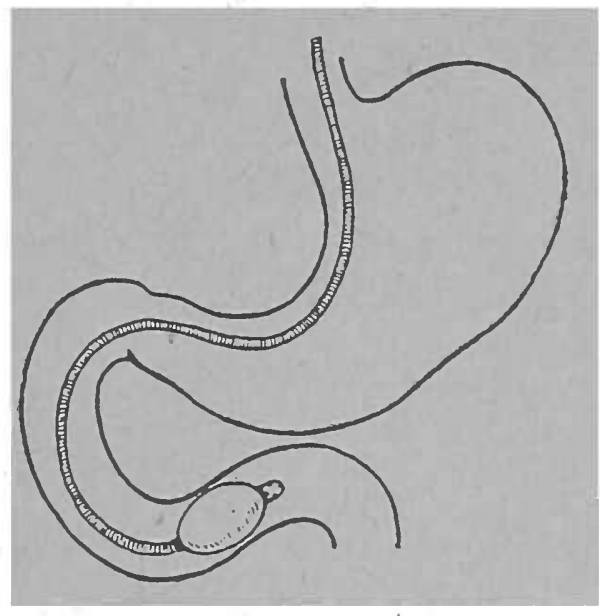

B

FIG. 5

Sonda dupla de Miller-Abbott. Caracterisa-se por apresentar um pequeno balão em sua extremidade distal, o que disperta o peristaltismo intestinal.

O outro processo de descompressão intestinal é a enterostomia; essa operação de derivação externa da alça, feita acima do ponto de oclusãa, foi universalmente empregada por todos os cirurgiões, e nos livros de técnica, encontram-se numerosos processos descritos. Hoje, ápós a introdução da intubação e aspiração intestinal, tornou-se um processo de excepção, que se emprega em casos muito especiais. Essa intervenção não apresenta nenhuma vantagem sobre a aspiração continua por sonda, e as desvantagens são as seguintes:

1 - é uma intervenção que não afasta a causa da oclusão intestinal. 
2 - produz uma fístula intestinal temporaria ou définitiva, conforme o processo empregado.

3 - drena unicamente a. alça derivada, e portanto não restitue o peristaltismo a todo o intestino quando existe um ileo paralítico.

4 - aumenta as causas do ileo, por ser uma intervenção, e, futuramente pode favorecer uma nova oclusão, por bridas.

Hoje, a enterostomia é uma operação excepcional, somente indicada, após o estudo metódico de cada caso. Uma excepção existe para as oclusões sigmoidianas, pois nessas circunstâncias a enterostomia constitue, por si, um tratamento da causa, da oclusão e não tem somente a finalidade de descompressão; assim, por exemplo, em um caso de oclusão do reto ou do colon pélvico por um cancer, lançamos mão dà derivação externa do sigmoide, que não só afasta o quadro da oclusão intestinal, como constitue o primeiro tempo para a ressecção da neoplasia.

\section{RESTABELECIMENTO DA FUNÇÃO INTESTINAL PELA REMOÇÃO DA CAUSA DA OCLUSÃO}

A primeira pergunta que o cirurgião deve formular desde que o diagnostico de oclusão intestinal seja feito, é se a causa dessa oclusão pode ou não ser removida por uma intervenção e, no caso afirmativo, se essa intervenção deve ser imediata ou tardia. 'De qualquer maneira, nenhum caso pode ser operado em estado de intensa toxémia e desidratação, antes que as condições metabólicas gerais tenham sido corrigidas.

A consideração mais importante para a intervenção imediata é o estado da circulação sanguinea da alça ocluida. Já sabemos que as perturbações circulatórias das paredes do intestino podem ser causadas pela compressão direta dos vasos mesentéricos (como é o caso dos vôlvulos) ou pela distensão exagerada da alça ocluida, ou pela embolia ou trombose dos vasos mesentéricos. A consequencia inevitavel é a anoxemia tissular aguda, perda da viabilidade, necrose e perfuração acompanhada de peritonite mortal. A laparotomia deve ser imediata, para evitar os perigos decorrentes da contaminação peritonial. A operação a ser realisada depende das alterações anatomopatológicas existentes. 'Se as perturbações circulatórias desaparecem com a supressão da causa da oclusão, isto significa que a alça é viavel e portanto deve ser conservada; se, pelo contrário, as perturbações circulatórias são definitivas, a alça não é viavel, e deve ser ressecada.

Quando o cirurgião se convencer de que a causa da oclusão sómente será removida por uma intervenção, porém, não existem perturbações circulatórias da alça ocluida (infelizmente isso acontece poucas vezes), a operação é adiada para uma ocasião mais oportuna, até que as alterações metabólicas gerais e as condições locais da alça distendida tenham sido cuidadosamente corrigidas. 
Quando a causa da oclusão não pode ser removida por uma intervenção, como é o caso do ileo paralítico, sómente a intubação e os medicamentos usuais citaḍos serão empregados.

Naturalmente deante de cada caso particular o cirurgião lança mão de medidđs terapêuticas que se aplicam especialmente a esse caso, e que se devem associar ao plano geral de tratamento que delineamos em tão poucas palavras. Como exemplo, citamos o bloqueio do sistema simpático pelas anestesias raquidianas ou. para-vertebrais, para o tratamento do ịleo adinâmico, o emprego do recúbito ventral para o tratamento do ileo artério-mesentérico, etc.

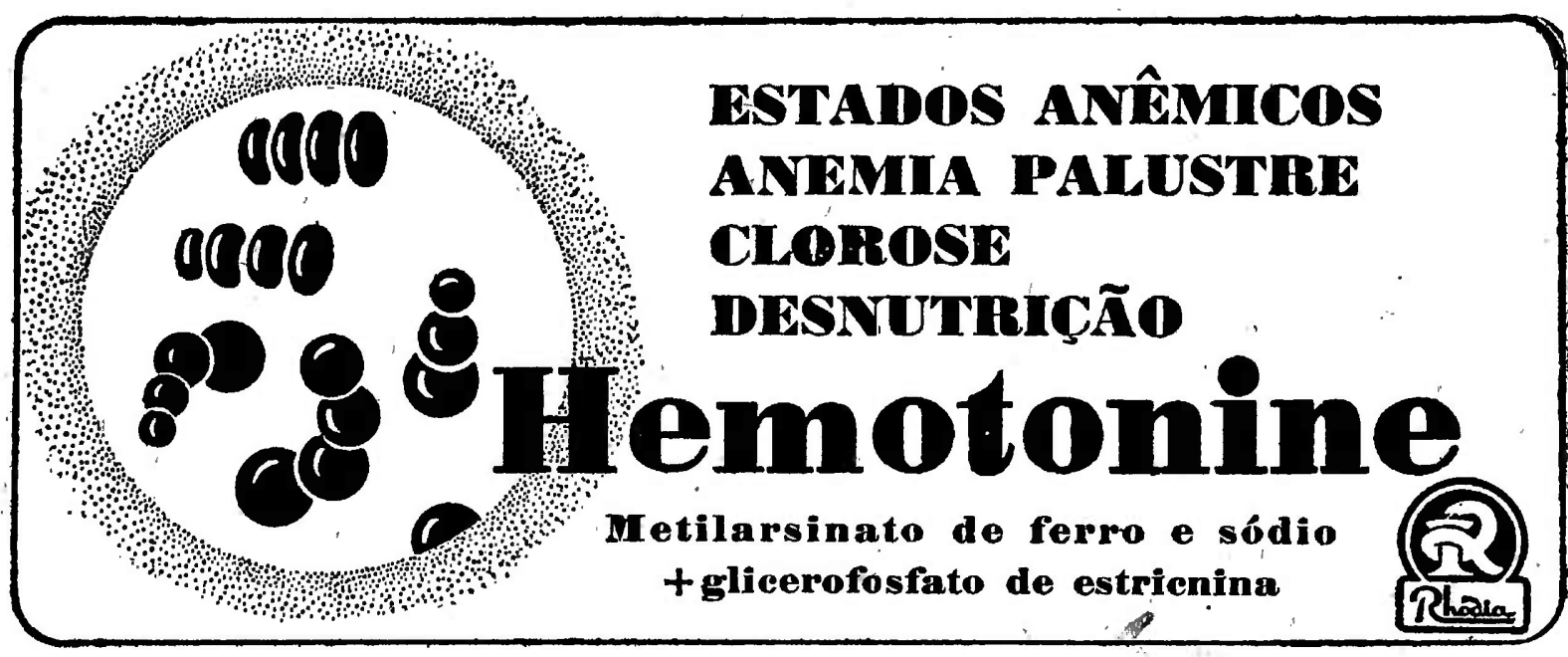

O departamento de

ADMINISTRACGAO PREDIAL DA

Caixa Geral de Emprestimos REGULARIZARÁ E AUGMENTARÄ O RENDIMENTO DOS PREDIOS DE V.S.

IDONEIDADE ABSOLUTA PRESTAÇÃO RIGOROSA DE CONTAS

\section{CAIXA GERAL DE EMPRESTIMOS}

Caisse Générale de Prêts Fonciers et Industriels

Rua Tabatinguera, 164 - Fone 2-4722 - SÃO PAULO 


\section{$\begin{array}{lllllllll}\mathbf{P} & \mathbf{Y} & \mathbf{O} & \mathbf{R} & \mathbf{R} & \mathbf{H} & \mathbf{E} & \mathbf{A}\end{array}$}

Gengivas sangrentas, dentes abalados e mau halito:

Resultados positivos em 8 dias, com o especifico

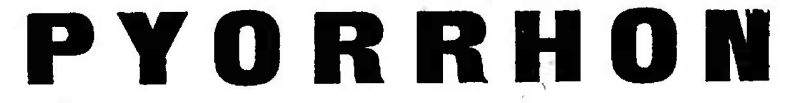

CONSULTAS: $30 \$ 000$.

DEMONSTRAÇõES PRATICAS AOS SENHORES MEDICOS E DENTISTAS

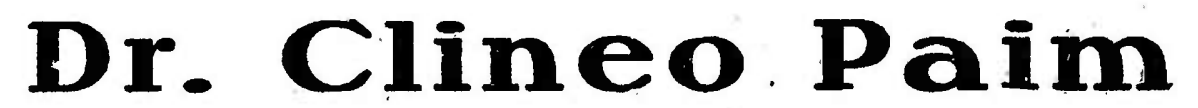

R. Barão de Itapetininga, $120-5 .^{\circ}$ andar - Salas, 505 e 506 (CASA GUATAPARÃ)

TELEFONE: 4-4050 — SÃO PAULO

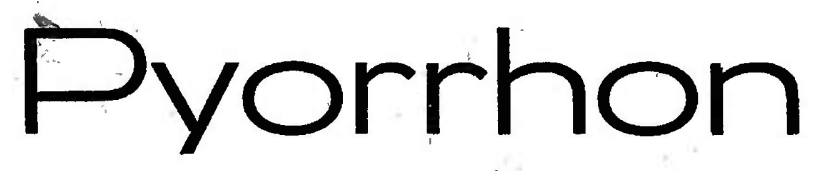

Un medicamento que veio resolver os casos de Gengivites e Pyorrhéa

A TEST A D O

E' para mim um prazer atestar que venho empregando em minha clinica com os mais brilhantes resultados, o Pyorrhon, medicamento de escol para o tratamento da Piorrhéa Alveolar e das Gengivites.

Tambem venho calorosamente recomendando o seu uso aos meus pacientes, porque assim fazendo estes teem assegurada a perfeita saude do seu meio bucal.

O Pyorrhon é um preparado que pela propaganda honesta com que é lançado e pelos seus meritos, merece da nossa classe a melhor acolhida.

São Paulo, 6 de Outubro de 1939.

Octavio Demacq Rosas.

Receite PYORRHON aOs seus clientes 